\title{
PENGGUNAAN LUMPUR AKTIF SEBAGAI MATERIAL UNTUK BIOSORPSI PEWARNA REMAZOL
}

\section{ACTIVATED SLUDGE USAGE FOR REMAZOL DYES BIOSORPTION}

\author{
Dewi Yuanita*, Endang Widjajanti dan Sulistyani \\ Jurusan Pendidikan Kimia Universitas Negeri Yogyakarta \\ *e-mail: dewiyuan@yahoo.com
}

\begin{abstract}
ABSTRAK
Penelitian ini bertujuan untuk mengetahui massa biosorben optimum, waktu kontak optimum dan konsentrasi pewarna optimum dalam biosorpsi lumpur aktif terhadap pewarna remazol teknis serta mengetahui pengaruh proses biosorpsi terhadap kadar COD (Chemical Oxygen Demand) pewarna remazol teknis. Proses biosorpsi dilakukan dengan sistem batch pada berbagai variasi massa biosorben, waktu kontak dan konsentrasi pewarna remazol teknis. Larutan pewarna remazol teknis sebelum dan sesudah biosorpsi dianalisis secara kuantitatif dengan spektrofotometer UV-Vis. Penentuan kadar COD dilakukan pada larutan remazol teknis sebelum dan sesudah adsorpsi. Efisiensi biosorpsi dinyatakan dalam bentuk konsentrasi teradsorpsi dibagi konsentrasi mula-mula larutan dan dikalikan 100\%. Hasil penelitian menunjukkan bahwa: massa lumpur aktif yang memberikan efisiensi terbesar pada biosorpsi remazol blue yaitu 5 gram dengan efisiensi biosorpsi 6,83\% sedangkan untuk remazol red adalah 150 gram dengan efisiensi biosorpsi $67,19 \%$. Waktu optimum dalam biosorpsi remazol blue menggunakan lumpur aktif adalah 15 menit dengan efisiensi biosorpsi 7,98\%, sedangkan untuk remazol red adalah 75 menit dengan efisiensi biosorpsi 9,30\%. Konsentrasi optimum dalam biosorpsi remazol blue menggunakan lumpur aktif adalah 200 ppm dengan efisiensi biosorpsi 6,19\% dan untuk remazol red $600 \mathrm{ppm}$ dengan efisiensi biosorpsi 9,10\%. Kadar COD pewarna remazol blue mengalami penurunan sebesar 22,22\% setelah proses biosorpsi dengan lumpur aktif.
\end{abstract}

Kata kunci : adsorpsi, lumpur aktif, remazol teknis

\begin{abstract}
This study aimed to determine the optimum biosorbent mass, optimum contact time and optimum concentration of dye on biosorption efficiency of activated sludge toward technical remazol dyes and to know the effect of the biosorption process of the COD (Chemical Oxygen Demand) value in technical remazol dyes solution. Biosorption process was done in batch system by conditioning the variation of the mass of Biosorbent, contact time and concentration of technical remazol dyes. Technical remazol dyes solution before and after biosorption were quantitatively analyzed by UV-Vis spectrophotometer and COD reactor. Adsorption efficiency expressed in terms of concentration of adsorbed dyes divided by the initial concentration of dye solution and multiplied by $100 \%$. The results showed that: the optimum mass biosorbent for remazol blue and red were 5 gram and 150 gram with biosorption efficiency $6,83 \%$ and $67,19 \%$ respectively. The optimum contact time for remazol blue and red were 15 minutes and 15 minutes with biosorption efficiency $7,98 \%$ and $9,30 \%$ respectively. The optimum dye concentration for remazol blue and red
\end{abstract}


were $200 \mathrm{ppm}$ and $600 \mathrm{ppm}$ with biosorption efficiency 6,19\% and 9,10\% respectively. COD value technical remazol decreased after adsorption process by activated sludge.

Keywords : activated sludge, adsorption, remazol dye

\section{PENDAHULUAN}

Industri tekstil yang berkembang dewasa ini menggunakan pewarna dalam proses produksinya. Penggunaan pewarna ini mengakibatkan adanya limbah pewarna dalam proses produksinya. Limbah pewarna ini bila tidak diolah dapat mengakibatkan terjadinya pencemaran lingkungan khususnya pencemaran terhadap perairan.

Zat warna umumnya bersifat toksik sehingga membahayakan bagi makhluk hidup. Zat warna juga dapat mengabsorp sinar matahari dengan kuat sehingga menurunkan intensitas sinar matahari yang dapat diabsorb oleh organisme seperti tanaman dalam air dan fitoplankton dalam proses fotosintesis. Hal ini akan mengakibatkan turunnya DO (dissolve oxygen) dalam ekosistem perairan dan berakibat pada peningkatan COD (Chemical Oxygen Demand) (Sharma, et al., 2012).

Salah satu pewarna yang sering digunakan adalah jenis remazol brilliant blue $R$ dan remazol red. Zat warna ini merupakan senyawa heterosiklis dengan unsur pembentuknya dari quinon. Antraquinon terdiri dari cincin benzene dengan gugus hidroksil yang disebut phenol. Phenol sangat tahan terhadap oksidasi. (Muslimah dan Kuswytasari, 2013).

Untuk menghilangkan dampak negatif dari limbah zat warna, diperlukan suatu perlakuan untuk mengurangi atau bahkan menghilangkan limbah pewarna dengan cara tertentu agar tidak membahayakan dan mencemari lingkungan sekitar. Salah satu cara yang dapat dilakukan adalah dengan metode biosorpsi untuk mengurangi konsentrasi limbah pewarna agar tidak membahayakan dan mencemari lingkungan saat dibuang di alam.

Biosorpsi menggunakan lumpur aktif merupakan metode yang efektif untuk menurunkan konsentrasi zat warna dalam limbah. Biosorpsi melibatkan kombinasi dari mekanisme transport aktif dan pasif yang dimulai dari difusi adsorbat menuju permukaan sel mikroba (Ratnamala dan Brajesh, 2013).

Lumpur aktif merupakan salah satu bahan yang potensial untuk mengolah limbah pewarna. Lumpur aktif merupakan limbah yang berasal dari industri-industri tertentu yang mengandung biomassa yang mempunyai kemampuan untuk mengadsorpsi suatu adsorbat(http://www.kelair.bppt.go.id/Sit pa/Artikel/Tekstil/tekstil.html).

Pemanfaatan lumpur aktif sebagai adsorben dinilai menguntungkan karena lumpur ini merupakan limbah yang tidak memiliki nilai ekonomi sehingga pemanfaatan material ini akan dapat meningkatkan dayaguna serta nilai ekonomi. Selain itu, penggunaan lumpur aktif ini sangat mendukung prinsip zerowaste, khususnya pada industri-industri yang menghasilkan lumpur aktif sebagai produk samping. Namun, lumpur aktif belum banyak digunakan sebagai adsorben dan pemanfaatan biomassa sebagai adsorben seperti lumpur aktif ini masih kurang popular dibandingkan dengan adsorben-adsorben lain seperti arang aktif, silika gel, alumina dan zeolit. 


\section{METODE PENELITIAN}

\section{Alat dan Bahan}

Alat-alat yang digunakan meliputi: spektrofotometer UV-VIS, gelas beker, aerator, pipet ukur, labu takar, pipet tetes, timbangan analitik, $\mathrm{pH}$ meter, corong, tabung reaksi, rak tabung reaksi, stopwatch.

Bahan yang diperlukan dalam penelitian ini meliputi: lumpur aktif, serbuk pewarna remazol blue dan remazol red teknis, akuades, kertas saring

\section{Prosedur Penelitian}

Biosorpsi dilakukan dengan cara mengambil lumpur aktif sebanyak 1 gram lalu dimasukkan ke dalam Erlenmeyer $250 \mathrm{~mL}$, ke dalam lumpur aktif tersebut ditambahkan larutan pewarna remazol blue 100 ppm sebanyak $100 \mathrm{~mL}$. Larutan diaduk dengan spatula selanjutnya didiamkan sambil diaerasi selama waktu biosorpsi 15 menit dihitung saat mulai diaduk. Larutan disaring dan diambil filtratnya. Absorbansi larutan sebelum dan sesudah biosorpsi diukur menggunakan spektofotometer UV-Vis. Langkah tersebut diulangi untuk variasi massa lumpur aktif 2, 3, 4, 5 gram pada pewarna remazol blue dan untuk variasi massa.1, 15, 30, 50, 100, 110, 150 gram pada remazol red. Biosorpsi juga dilakukan pada waktu kontak $3,6,12$, $15,30,60,120,150$, serta 180 menit untuk remazol blue dan 10, 15, 20, 30, 45, 75, 90, 105, dan 120 menit untuk remazol red. Biosorpsi dengan variasi konsentrasi pewarna dilakukan pada konsentrasi 100, 200, 300, 400, serta 500 ppm untuk remazol blue dan 200, 300, 400, 500, dan 600 ppm untuk remazol red.

Pewarna remazol blue teknis 300 ppm sebelum dan sesudah biosorpsi selama 15 menit diukur kadar COD dengan menggunakan reaktor COD.

\section{Perhitungan Efisiensi Biosorpsi}

Efisiensi biosorpsi adalah
perbandingan antara konsentrasi
pewarna teradsorpsi dengan konsentrasi
pewarna sebelum adsorpsi yang dihitung
dengan rumus :

$$
\text { Efisiensi biosorpsi }=\frac{\mathrm{Co}-\mathrm{Ca}}{\mathrm{Co}} \times 100 \%
$$

Keterangan :

$\mathrm{Co}=$ konsentrasi sampel sebelum diadsorpsi (mg/L)

$\mathrm{Ca}=$ konsentrasi sampel setelah diadsorpsi $(\mathrm{mg} / \mathrm{L})$

\section{HASIL DAN PEMBAHASAN}

\section{Biosorpsi Pewarna Remazol oleh Lumpur Aktif}

Proses biosorpsi pewarna remazol oleh lumpur aktif terjadi diawali dengan proses adsorpsi sebagai sistem nonenzimatik dilanjutkan dengan adanya kemampuan degradasi oleh isolat karena terjadinya aktivitas metabolisme dengan sistem enzimatik (Dewi, 2005). Dalam penelitian ini, biosorpsi pewarna remazol teknis dilakukan dengan cara aerob menggunakan bakteri-bakteri aerob dalam lumpur aktif dengan bantuan aerator sebagai pemasok oksigen murni bagi bakteri-bakteri tersebut. Adanya oksigen dalam proses adsorpsi ini berfungsi untuk memperpanjang masa hidup mikroorganisme di dalam lumpur aktif, sehingga pada waktu adsorpsi yang ditentukan, mikroorganisme tetap hidup dan mengadsorpsi lebih banyak pewarna.

Bakteri aerob memerlukan oksigen dalam menguraikan senyawa organik untuk memperoleh energi yang digunakan untuk pertumbuhan dan multiplikasi sel (Hammer, 1986). Selain itu, aerasi berfungsi sebagai sumber oksigen dalam proses oksidasi pewarna. Pada biosorpsi dengan bakteri aerob 
secara umum, penghilangan warna diawali dengan peristiwa adsorpsi oleh matriks (membran plasma) dari bakteri aerob selanjutnya diteruskan oleh bakteri aerob dengan memproduksi metabolit, misalnya berupa enzim (Awaluddin, 2001). Dekolorisasi non-enzimatik ini terjadi pada saat peristiwa adsorpsi pewarna remazol oleh matriks (membran plasma) dari bakteri aerob yang terdapat dalam lumpur aktif, karena fungsi membran plasma dari bakteri aerob tersebut yaitu sebagai rintangan selektif yang memungkinkan aliran oksigen, nutrien, dan limbah yang cukup untuk melayani seluruh volume sel dari bakteri tersebut. Bakteri aerob dalam lumpur aktif menggunakan karbon dan nitrogen dari pewarna remazol teknis tersebut sebagai sumber karbon dan nitrogen yang mendukung kehidupannya sehingga terjadi dekolorisasi enzimatik (Sharma, et al., 2009). Lumpur aktif dapat berperan sebagai biosorben dengan sisi aktif pada senyawa polimer ekstraseluler dan dinding sel bakteri (Kusmaya dan Halim, 2004). Umumnya biosorben mengandung $\beta$-D-glukosa berulang sebagai komponen utama dinding sel. Gugus yang berperan sebagai situs aktif adalah gugus hidroksil polar dalam selulosa (Kurniasari, 2010)

zat organik+mikroorganisme $\stackrel{\mathrm{O}_{2}}{\longrightarrow} \mathrm{CO}_{2}+\mathrm{H}_{2} \mathrm{O}+\mathrm{NH}_{3}+$ sel-sel baru

Beberapa penelitian menyatakan bahwa cara terbaik untuk melakukan dekolorisasi (penghilangan warna) adalah dengan penggabungan metode aerob dan anaerob. Saat proses anaerob, terjadi pemutusan molekul-molekul yang sangat kompleks menjadi molekulmolekul yang lebih sederhana, sehingga mudah terbiodegradasi oleh proses aerob menjadi $\mathrm{CO}_{2}, \mathrm{H}_{2} \mathrm{O}, \mathrm{NH}_{3}$ dan biomassa (Hammer, 1986). Dalam penelitian ini hanya dilakukan proses secara aerob saja sehingga efisiensi biosorpsi yang dihasilkan tidak terlalu tinggi.

Pengaruh Massa Biosorben terhadap Efisiensi Biosorpsi Lumpur Aktif pada Pewarna Remazol Teknis

Hubungan antara banyaknya
biosorben yang digunakan dengan
efisiensi adsorpsinya ditunjukkan pada Gambar 1 dan 2.

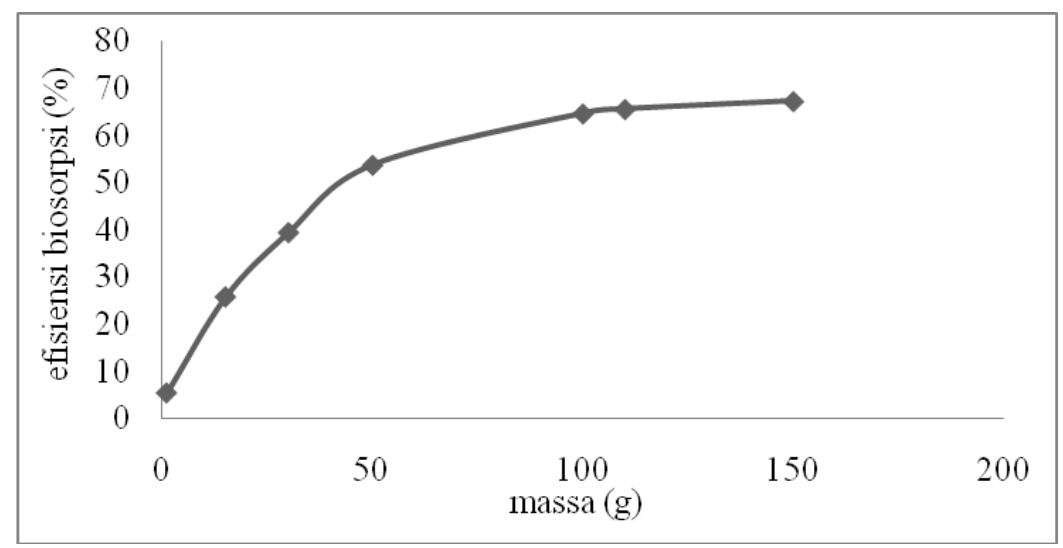

Gambar 1. Kurva hubungan antara efisiensi biosorpsi (\%) dan massa biosorben lumpur aktif (gram) pada remazol red 


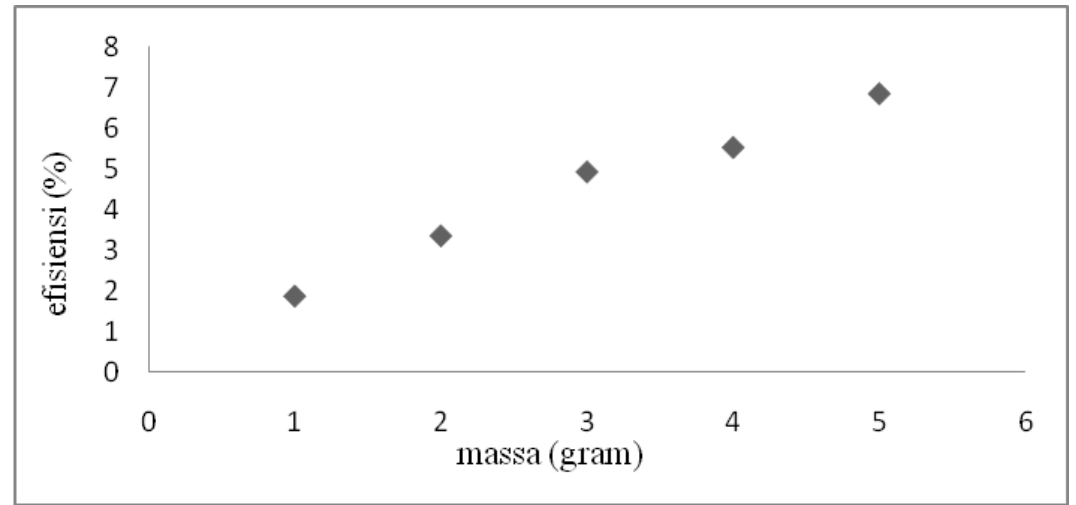

Gambar 2. Kurva hubungan antara efisiensi biosorpsi (\%) dan massa biosorben lumpur aktif (gram) pada remazol blue

Gambar 1 dan 2 menunjukkan bahwa semakin banyak biosorben yang digunakan (semakin besar massa lumpur aktif), semakin besar pula efisiensi adsorpsinya. Hal ini teramati pada adsorpsi lumpur aktif terhadap pewarna remazol blue dan red. Hal tersebut terjadi karena massa biosorben mempengaruhi banyaknya situs aktif dari biosorben. Dalam lumpur aktif, yang berperan sebagai situs aktif adalah mikroorganisme yang terkandung di dalamnya. Semakin besar massa lumpur aktif, maka semakin banyak pula situs aktif atau mikroorganisme dalam lumpur aktif yang dapat berinteraksi dengan pewarna remazol teknis (Puvaneswari, et al., 2006). Hal ini menyebabkan kemampuan lumpur aktif dalam proses dekolorisasi menjadi meningkat sehingga efisiensi biosorpsi akan semakin besar bila massa lumpur aktif yang digunakan semakin banyak. Nilai efisiensi biosorpsi terbesar untuk remazol blue dan remazol red diperoleh pada massa adsorben sebesar 5 gram dan 150 gram dengan efisiensi adsorpsi untuk remazol blue sebesar $6,83 \%$ dan untuk remazol red sebesar $67,19 \%$.

\section{Pengaruh Waktu Kontak pada Efisiensi Biosorpsi Lumpur Aktif terhadap Pewarna Remazol Teknis}

Waktu adsorpsi merupakan waktu yang digunakan untuk proses adsorpsi suatu adsorbat oleh suatu adsorben atau sering juga disebutkan sebagai waktu kontak antara adsorben dengan adsorbat. Waktu adsorpsi atau waktu kontak antara adsorbat dengan adsorben sangat mempengaruhi daya serap. Umumnya semakin lama waktu kontak maka efisiensi adsorpsi juga akan meningkat sampai pada waktu tertentu akan mencapai kondisi optimum dan setelah itu akan turun kembali (Khopkar, 1990).

Gambar 3 menunjukkan bahwa proses biosorpsi terjadi secara cepat pada awal waktu kontak kemudian lajunya menurun. Hal ini terjadi karena pada awal biosorpsi situs aktif masih kosong dan konsentrasi pewarna masih tinggi sehingga menjadi driving force bagi lumpur aktif dalam proses biosorpsi (Ratnamala dan Brajesh, 2013).

Pada remazol blue terlihat bahwa untuk waktu kontak 50 menit terjadi penurunan efisiensi biosorpsi. Hal ini menunjukkan bahwa pada waktu tersebut situs aktif pada permukaan sel dalam lumpur aktif sudah mulai jenuh sehingga proses biosorpsi tidak lagi maksimal. Efisiensi biosorpsi pewarna remazol red yang tertinggi diperoleh pada waktu kontak 75 menit dengan nilai efisiensi biosorpsi sebesar 9,30\%. Efisiensi biosorpsi pewarna remazol blue yang tertinggi diperoleh pada waktu kontak 15 menit dengan nilai efisiensi biosorpsi sebesar $7,98 \%$. 


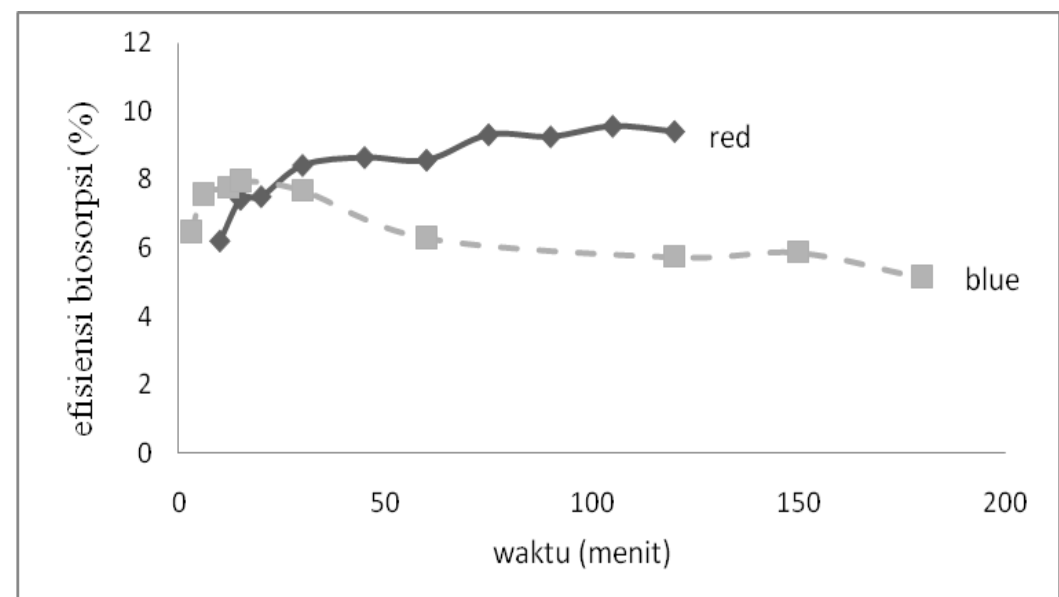

Gambar 3. Kurva hubungan antara efisiensi biosorpsi (\%) dan waktu kontak biosorben lumpur aktif terhadap zat warna remazol (menit)

\section{Pengaruh Konsentrasi Pewarna terhadap Efisiensi Adsorpsi Lumpur Aktif pada Pewarna Remazol Teknis}

Gambar 4 menunjukkan bahwa kenaikan konsentrasi akan meningkatkan efisiensi biosorpsi pada konsentrasi 100 ke 200 ppm untuk remazol blue. Untuk pewarna remazol red semakin besar konsentrasi maka efisiensi biosorpsi menjadi semakin besar. Hal ini dapat disebabkan oleh bakteri pada lumpur aktif yang digunakan dalam proses biosorpsi mampu mengoksidasi senyawa organik sampel. Kenaikan konsentrasi zat warna tidak selalu menaikkan efisiensi biosorpsi, ini terjadi apabila telah tercapai kondisi kesetimbangan antara sorbat dan sorben yaitu pada 200 ppm dengan efisiensi biosorpsi 6,19\%. Penurunan efisiensi biosorpsi ini terjadi karena makin besar konsentrasi pewarna remazol teknis maka situs aktif yang dimiliki lumpur aktif telah jenuh karena permukaannya telah terisi penuh oleh pewarna remazol teknis, serta tidak mampu lagi berinteraksi dengan molekul adsorbat sehingga tidak mampu lagi menyerap pewarna yang konsentrasinya masih cukup besar (Ratnamala dan Brajesh, 2013). Konsentrasi optimum dalam biosorpsi remazol blue menggunakan lumpur aktif adalah 200 ppm dengan efisiensi biosorpsi 6,19\% dan untuk remazol red 600 ppm dengan efisiensi biosorpsi $9,10 \%$.

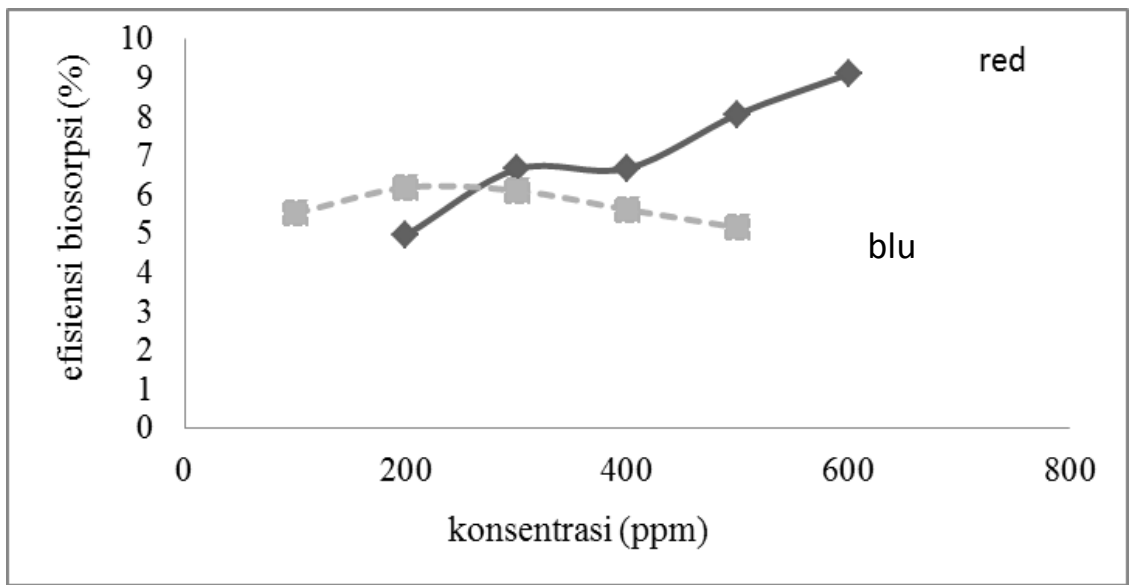

Gambar 4. Kurva hubungan antara efisiensi biosorpsi lumpur aktif (\%) dan konsentrasi pewarna remazol 


\section{Kadar COD Pewarna Remazol blue Teknis}

Nilai COD merupakan salah satu parameter untuk mengetahui suatu lingkungan tercemar atau tidak. Nilai COD atau kebutuhan oksigen kimia adalah jumlah oksigen $\left(\mathrm{mg} \mathrm{O}_{2}\right)$ yang dibutuhkan untuk mengoksidasi zat-zat organik yang ada dalam satu liter sampel air. Bila nilai COD semakin tinggi, berarti semakin tinggi pula beban cemaran yang ada pada suatu lingkungan tersebut (Sigit, 2004).

Hasil penelitian menunjukkan bahwa kadar COD dalam larutan pewarna remazol blue teknis $300 \mathrm{ppm}$ sesudah adsorpsi selama 15 menit ternyata mengalami penurunan sebesar $22,22 \%$ dari $1396,80 \mathrm{mg} / \mathrm{L}$ menjadi 1086,40 $\mathrm{mg} / \mathrm{L}$. Dari hasil tersebut terlihat bahwa bakteri-bakteri aerob yang terkandung dalam lumpur aktif berpengaruh dalam menurunkan kadar COD. Bakteri aerob dalam lumpur aktif telah berperan melakukan proses non-enzimatis maupun enzimatis terhadap pewarna remazol sehingga kadar pewarna remazol dalam larutan berkurang. Berkurangnya kadar pewarna remazol tentu saja ini akan menyebabkan jumlah oksigen $\left(\mathrm{mg} \mathrm{O}_{2}\right)$ yang dibutuhkan untuk mengoksidasi pewarna remazol yang ada dalam sampel menjadi lebih sedikit atau dengan kata lain nilai COD-nya turun. Atau dengan kata lain beban cemaran yang ada pada pewarna remazol teknis sesudah diadsorpsi oleh lumpur aktif mengalami penurunan dibandingkan dengan sebelum adsorpsi.

\section{KESIMPULAN}

Massa lumpur aktif yang memberikan efisiensi terbesar pada biosorpsi remazol blue yaitu 5 gram dengan efisiensi biosorpsi $6,83 \%$ sedangkan untuk remazol red adalah 150 gram dengan efisiensi biosorpsi 67,19\%.
Waktu optimum dalam biosorpsi remazol blue menggunakan lumpur aktif adalah 15 menit dengan efisiensi biosorpsi $7,98 \%$, sedangkan untuk remazol red adalah 75 menit dengan efisiensi biosorpsi 9,30\%. Konsentrasi optimum dalam biosorpsi remazol blue menggunakan lumpur aktif adalah 200 ppm dengan efisiensi biosorpsi 6,19\% dan untuk remazol red 600 ppm dengan efisiensi biosorpsi 9,10\%. Kadar COD pewarna remazol blue mengalami penurunan sebesar $22,22 \%$ setelah proses biosorpsi dengan lumpur aktif.

\section{DAFTAR PUSTAKA}

Awaluddin. 2001. Biodekolorisasi. Bogor : Institut Pertanian Bogor

Dewi, R. S. 2005. Potensi Bakteri Limbah Industri Tekstil Sebagai Agen Pendekolorisasi Pewarna Azo Sumber Pencemaran Warna Perairan. Di Dalam: Prosiding Seminar Nasional dan Kongres Biologi XII: Yogyakarta, 19-22 April 2005

Hammer, M. J. 1986. Water and Wastewater Technology. $2^{\text {nd }}$. ed. Canada: John Wiley \& Sons, Inc

Sigit, H. 2004. BOD dan COD Sebagai Parameter Pencemaran Air dan Baku Mutu Air Limbah. Bogor: IPB

Khopkar, S.M. 1990. Konsep Dasar Kimia Analitik. Jakarta: Penerbit Universitas Indonesia

Kurniasari, L. 2010. Pemanfaatan Mikroorganisme dan Limbah Pertanian sebagai Bahan Baku Biosorben Logam Berat. Momentum. 6(II)

Kusmaya, M dan M. B. Halim. 2004. Adsorpsi Kadmium (II) dan Kromium (III) dalam Air oleh Lumpur Aktif. Diakses dari 
digilib.ac.id pada tanggal 20 Juni 2014

Sharma, N., D.P. Tiwari, S.K. Singh. 2012. Decolorization of Synthetic Dyes by Agricultural Waste-A review. IJSER. Vol 3 Issue 2

Puvaneswari, N., Muthukrishnan, J. and Gunasekaran, P. 2006. Toxicity Assessment and Microbial Degradation of Azo Dyes. Indian Journal of Experimental Biology. Vol. 44, Hlm.: 618-626

Ratnamala and Brajesh. 2013. Biosorption of Remazol Navy Blue Dye from an Aqueous Solution using Pseudomonas putida. IJSET. Vol 2. No.1.
Sharma, P., Singh, L., Dilbaghi, N. 2009. Optimization of Process Variable for Decolorization of Disperse Yellow 211 by Bacillus subtilis using Box-Behnken Design. Journal of Hazardous Materials. Vol 164. pp 1024-1029

Muslimah, S dan N. D Kuswytasari. 2013. Potensi Basidiomycetes Koleksi Biologi ITS sebagai Agen Biodekolorisasi Zat Warna RBBR. Jurnal sains dan Seni Pomits. 2(I)

(http://www.kelair.bppt.go.id/Sitpa/Artik el/ Tekstil/tekstil.html) Diakses pada tanggal 10 Oktober 2012 